\title{
Management of naso-septal deformity in childhood: Long-term results
}

\author{
Francesco Dispenza ${ }^{a, *}$, Carmelo Saraniti ${ }^{a}$, Daniela Sciandra ${ }^{a}$, \\ Gautham Kulamarva $^{\mathrm{b}}$, Carlo Dispenza ${ }^{\mathrm{a}}$ \\ ${ }^{a}$ Dipartimento Scienze Otorinolaringoiatriche, Università degli Studi di Palermo, Italy \\ ${ }^{\mathrm{b}}$ ENT Clinic, Nayak's Road, Kasaragod, India
}

Received 30 July 2008; accepted 26 February 2009

Available online 2 May 2009

\begin{abstract}
Objective: The classical teaching advocates a conservative approach for children presenting with various naso-septal deformities. It may not be appropriate especially when it causes nasal obstruction to the growing child. This study has two main purposes: to contribute in identifying the correct selection criteria for surgical management of pediatric patients and in selecting the most appropriate surgical technique.

Material and method: We reviewed a series of 46 cases of post-traumatic septal and naso-septal deformity not managed promptly or with recurrence of nasal deviation, following bones fracture correction alone. The mean follow-up was 10 years.

Results: Patients with naso-septal deformity managed only by septoplasty had accentuation of nasal pyramid deformity; those treated by septorhinoplasty showed a good aesthetic and functional result after long-term follow-up.

Conclusion: Our series results demonstrated that the best results were obtained when we correct all evident alterations of nasal septum and pyramid at a single stage. Unsuccessful results seen in our first group suggest that immediate correction of septum alone with delayed management of nasal pyramid deformity leads to a poorer outcome.

(C) 2009 Elsevier Ireland Ltd. All rights reserved.
\end{abstract}

Keywords: Septoplasty; Rhinoplasty; Childhood nasal deformity; Nasal trauma; Septal deviation

\section{Introduction}

Surgery for deformities of the nasal pyramid and septum during childhood is shrouded with controversies. Every surgical procedure of the nose at this young age may cause developmental arrest [1]. Even the results may not be long lasting in time, as the nose is a growing structure. A review of literature showed that there is neither any solution to this problem nor any guidelines for management, yet [2-5]. True incidence of septal deviation in childhood is unknown. Gray reported that in $58 \%$ of 2380 children studied a septal deviation was present [6]. Trauma is the most common cause for naso-septal deviation during childhood. Apart from this, cranio-facial growth irregularity may also cause the formation of a ridge between septal cartilage and vomeral bone, often associated with turbino-septal contact. Connate

\footnotetext{
* Corresponding author. Tel.: +39 3334565471.

E-mail address: francesco.dispenza@poste.it (F. Dispenza).
}

septal deformity due to trauma during intrauterine life or during transit in birth canal has also been reported as a cause for septal deviation, in the literature [7]. Surgical correction of septal deviation is indicated, irrespective of age, if such deformity causes nasal stenosis and oral breathing. Conservative management may worsen the nasal morphology, because deviated nasal septum may exert traction during growth, to normal alar and triangular cartilages not involved in previous trauma. Natural history of nasal trauma in early years demonstrates that, effect of a misdiagnosed trauma can appear during developmental age, and a nasal deformity due to unmanaged fracture becomes worse during growth. Cartilaginous arch involvement may cause narrowing of the nostril and height and/or length asymmetry of nasal pyramid. Delayed management of these alterations requires difficult surgical procedures with not always good results. Moreover the impaired nasal patency may exert negative effect on other systems and organs that play a role in the somatic and psychic development of the little patient. 
Such effects are seen mainly on the maxillo-facial skeleton and rib cage, but also seen as dysventilatory syndrome of middle ear and paranasal sinuses, vocal tract disorders and difficulty in sleep. This study has two main purposes: to contribute in identifying the correct selection criteria for surgical management of naso-septal deformities in pediatric patients and in selecting the most appropriate surgical technique for such patients.

\section{Material and method}

The study was designed as a retrospective review of charts of 46 patients with post-traumatic naso-septal deviation, not managed promptly or with recurrence of naso-septal deviation following initial bone fracture correction alone. The ethical committees of our institution have approved this study and subjects gave informed consent to the work.

Sixteen patients out of 46 affected by septal deviation, without nasal pyramid alterations, underwent septoplasty and were excluded from results evaluation.

Remaining 30 patients with naso-septal deviation were divided in two groups depending on surgical procedure performed (Table 1).

The first group included 16 patients suffering from septal deviation and nasal pyramid deformity. These patients too underwent septoplasty alone. The second group had 14 patients in them affected, as those in the first group, by nasal septum and nasal pyramid deformation. These patients were managed by septoplasty and partial rhinoplasty (i.e. reopening of old fracture lines and reduction). Patients were followed up post-operatively to see for any recurrence of septal deviation as well as the overall effect on the nasal pyramid. The senior author (CD) performed all operations.

The long-term efficacy of treatment was determined by: (1) evidence of residual septal deviation, (2) symmetry of nasal pyramid, and (3) subjective satisfaction of patients for both respiratory function and aesthetic appearance.

\subsection{Surgical technique}

The key in performing a conservative septoplasty is to obtain good visualization of the deviated segment of nasal septum during surgery. Unless we do this, there is always a

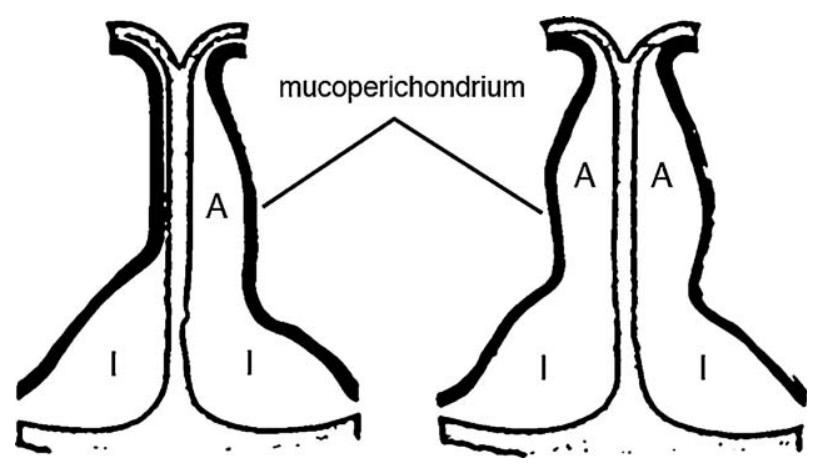

Fig. 1. Scheme of tunnels in nasal septal dissection. The mucoperichondrium is dissected from quadrangular cartilage forming three or four tunnels. (A) Anterior tunnel and (I) inferior tunnel.

risk of removing normal septal segments, apparently causing the deformity, using unnecessarily complex surgical techniques. Cottle's maxilla-premaxilla approach allows good exposure of all the septal segments [2,3]. We sometimes adopt the more extensive form of this approach, in children, which entails the formation and reunion of four tunnels. Sometimes it is sufficient to do just one anterior tunnel and one or two posterior tunnels (Fig. 1). The mucoperichondrium is dissected from quadrangular cartilage maintaining its integrity. Deformity of nasal septum can be due to parallel, perpendicular or oblique fractures with respect to the maxillary plane (Fig. 2). Occasionally parallel and oblique fractures coexist. Deformity due to parallel fractures can be usually corrected by inferior and posterior chondrotomy, leaving the quadrangular cartilage in situ (Fig. 3). This way we can maintain the articulation with triangular cartilage intact. Next step is to remove the inferior part of quadrangular cartilage, if it exceeds or is luxated towards the floor of nasal cavity. Later, depending on whether they are deviated or not, vomeral bone and perpendicular lamina of ethmoid are corrected. While performing all these steps, adequate care is taken to avoid any superimposition of septal segments (Fig. 3). Deviations due to perpendicular/oblique fractures with coexistent nasal pyramid deformities and obstruction of the valvular area, often requires total removal of the quadrangular cartilage, remodelling it outside the body and replacing it back in its place with external guide stitches (Figs. 4 and 5). These stitches are positioned in order to sustain the point where septum, nasal bone and triangular cartilage join together

Table 1

Groups of patients enrolled in this study depending on nasal septum and pyramid alterations and on surgical procedure performed with results obtained.

\begin{tabular}{|c|c|c|c|c|c|c|}
\hline Groups & $\begin{array}{l}\text { Number of } \\
\text { patients }\end{array}$ & Mean age & $\begin{array}{l}\text { Mean duration } \\
\text { of observation }\end{array}$ & Deformity & Technique & Outcome \\
\hline I & 16 & $\begin{array}{l}9 \text { years } \\
\text { (range } 6-12 \text { years) }\end{array}$ & $\begin{array}{l}12 \text { years } \\
\text { (range } 8-15 \text { years) }\end{array}$ & Naso-septal & Septoplasty & $\begin{array}{l}\text { In } 25 \% \text { of cases recurrence of septal deviation } \\
\text { Nasal pyramid deformity accentuated in } 100 \%\end{array}$ \\
\hline II & 14 & $\begin{array}{l}9 \text { years } \\
\text { (range } 6-12 \text { years) }\end{array}$ & $\begin{array}{l}14 \text { years } \\
\text { (range } 10-20 \text { years) }\end{array}$ & Naso-septal & Septorhinoplasty & $\begin{array}{l}\text { In } 2 \text { cases asymptomatic recurrence } \\
\text { of septal deviation } \\
\text { Good aesthetic result in all cases with symmetric } \\
\text { nasal pyramid and growth of face }\end{array}$ \\
\hline
\end{tabular}




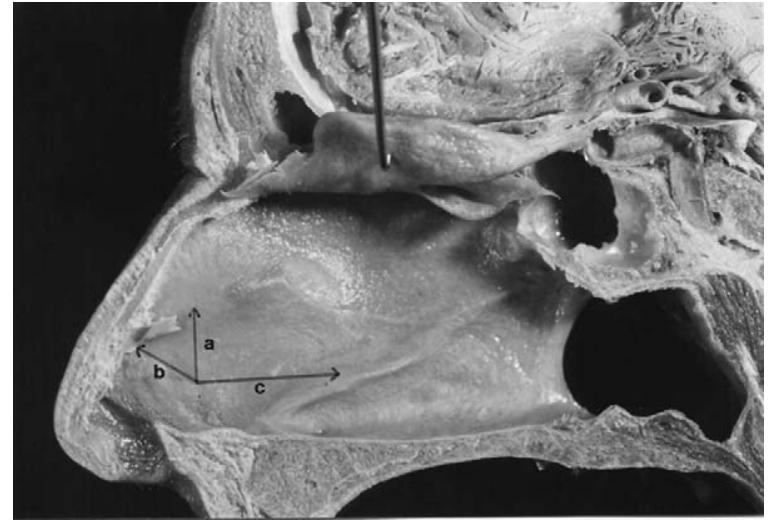

Fig. 2. Schematic draw on a cadaver nasal septum of fracture lines. (a) Vertical fracture, (b) oblique fracture, and (c) horizontal fracture.

(Cottle's "K area"), the nasal tip and columella. Correction of posterior deviation is achieved by targeted removal of deviated bony segments, following posterior chondrotomy. Sometimes the deviated segment needs to be replaced back between the mucoperichondral/mucoperiosteal layers after proper remodelling, in order to reduce empty segments of the septum, thereby giving it better stability. If there is deviation of either bony or cartilaginous arch, we prefer to do a partial rhinoplasty. This latter is done by opening the old fracture lines with a thin osteotome, performing low to high basal osteotomies. Disarticulation of triangular cartilages from the quadrangular is the next step. This approach allows good correction of oblique septal deviations, that often include deformity of bony-cartilaginous junction, and helps in restoring normal valvular angle. The nasal dorsum is never lowered. If there is any caudal dislocation of the septum, a columellar pouch is created to receive the inferior aspect of quadrangular cartilage.

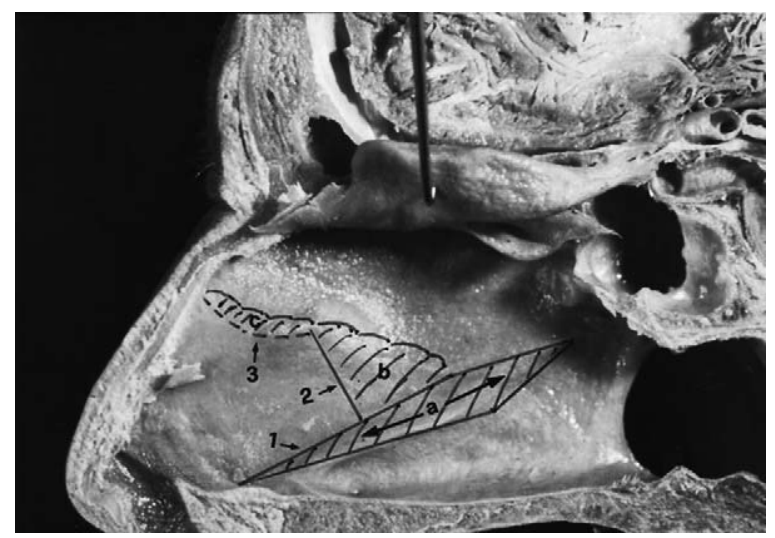

Fig. 3. Correction scheme: (1) inferior chondrotomy, (2) posterior chondrotomy, and (3) detachment of quadrangular cartilage and perpendicular ethmoidal lamina contact; (a) removal of deviated vomeral bone (spurs and ridge), (b) removal of posterior portion of quadrangular cartilage, and (c) correction of perpendicular ethmoidal lamina, to avoid any superimposition of septal segments.

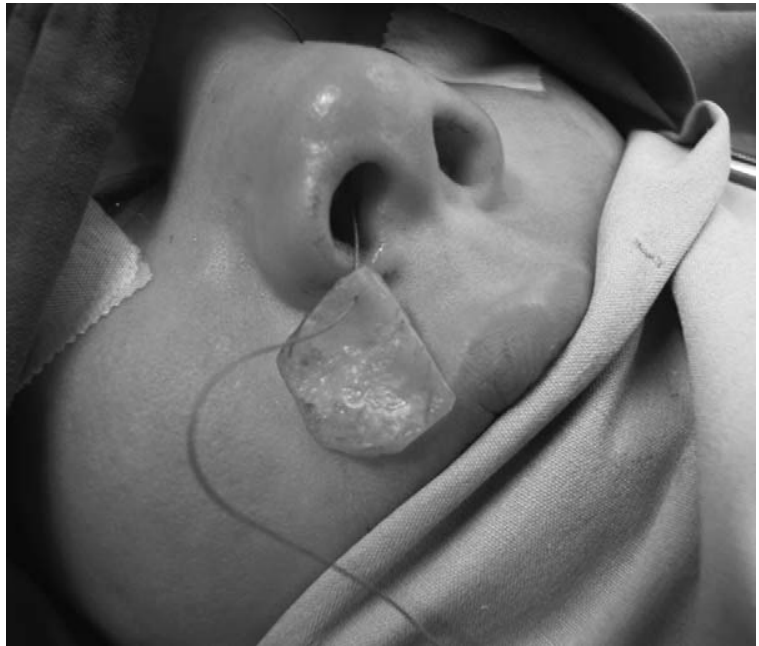

Fig. 4. Total removal of the quadrangular cartilage, remodelling and replacing it back in its place with external guide stitches-stitch in the "K area".

\section{Results}

The patients were aged between 4 and 12 years, and had a follow-up period of 7-20 years (mean follow-up 10 years).

The 16 patients suffering for isolate septal deviation had no objective growth deficit of the nasal pyramid during follow-up after operation. The subjective functional results in this series were also good. Only one patient $(6.3 \%)$ had sub-luxation of inferior aspect of quadrangular cartilage.

The first group included patients aged between 6 and 12 years. Four patients $(25 \%)$ presented with a recurrence of septal deviation. Nasal pyramid deformity was accentuated in all patients (Figs. 6 and 7).

The second group consisted of children aged from 6 to 12 years. All patients had acceptable aesthetic results (Figs. 8 and 9) and two patients (14.7\%) presented with asymptomatic recurrence of septal deviation (Table 1).

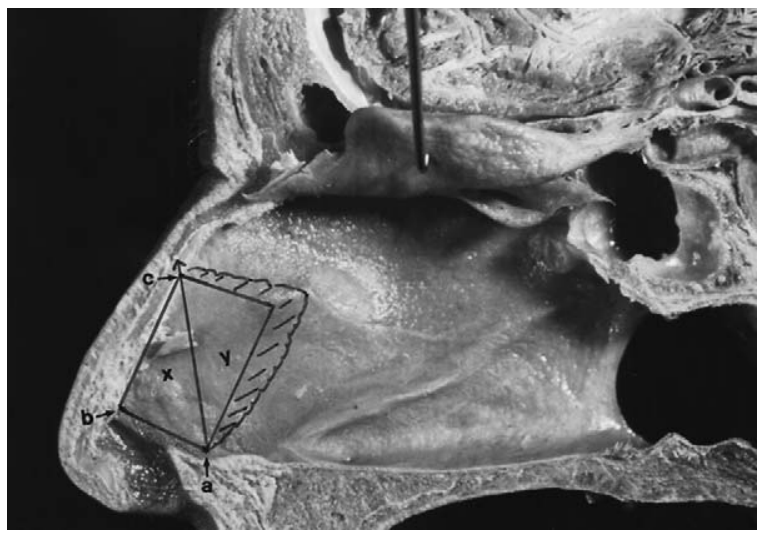

Fig. 5. Scheme of replacing the remodelled quadrangular cartilage. The cartilage may have a triangular (x) or quadrangular (y) shape. The new quadrangular cartilage have to: lay on nasal spine (a), sustain the nasal tip (b), and sustain the "K area" (c). 

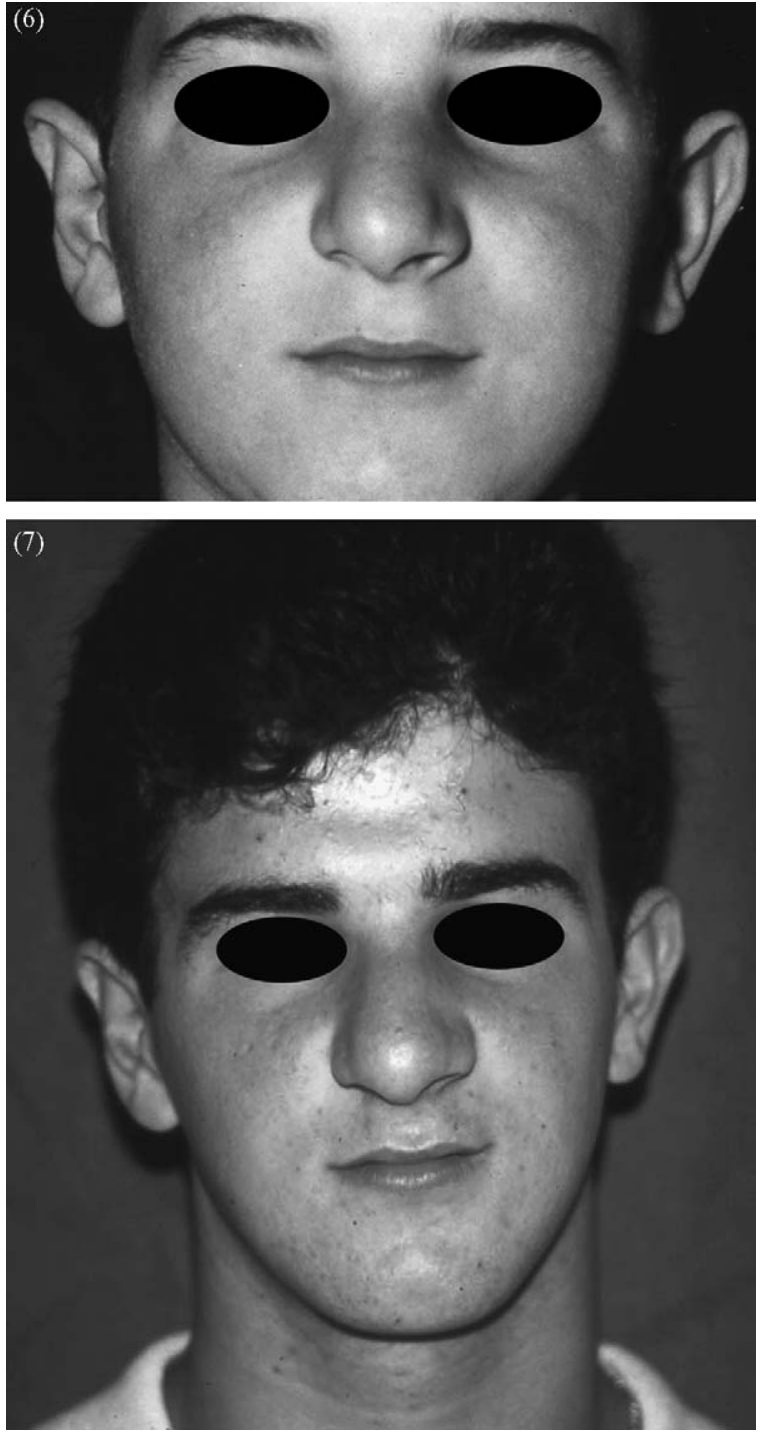

Figs. 6 and 7. Group I: 9 years follow-up; evidence of accentuated nasal pyramid deformity.

\section{Discussion}

It is known that nasal septum plays an important role in the harmonic growth of the face. Compelled oral breathing due to nasal obstruction during childhood, disrupts the normal development of skull base angle and consequently the normal maxillo-facial growth. This in turn can cause malocclusion and protrusion of maxillary bone, leading to a condition called as class II skeletal deformity, comparable to "facies adenoidea" [8,9]. If septal deviation occurs during the rapid phase of development, it may cause irregular growth of cartilaginous structure of the nasal vault including in those structures that were not originally affected by the trauma. Trauma may involve fracture of either bony or cartilaginous vault. If such injuries are not corrected at an early
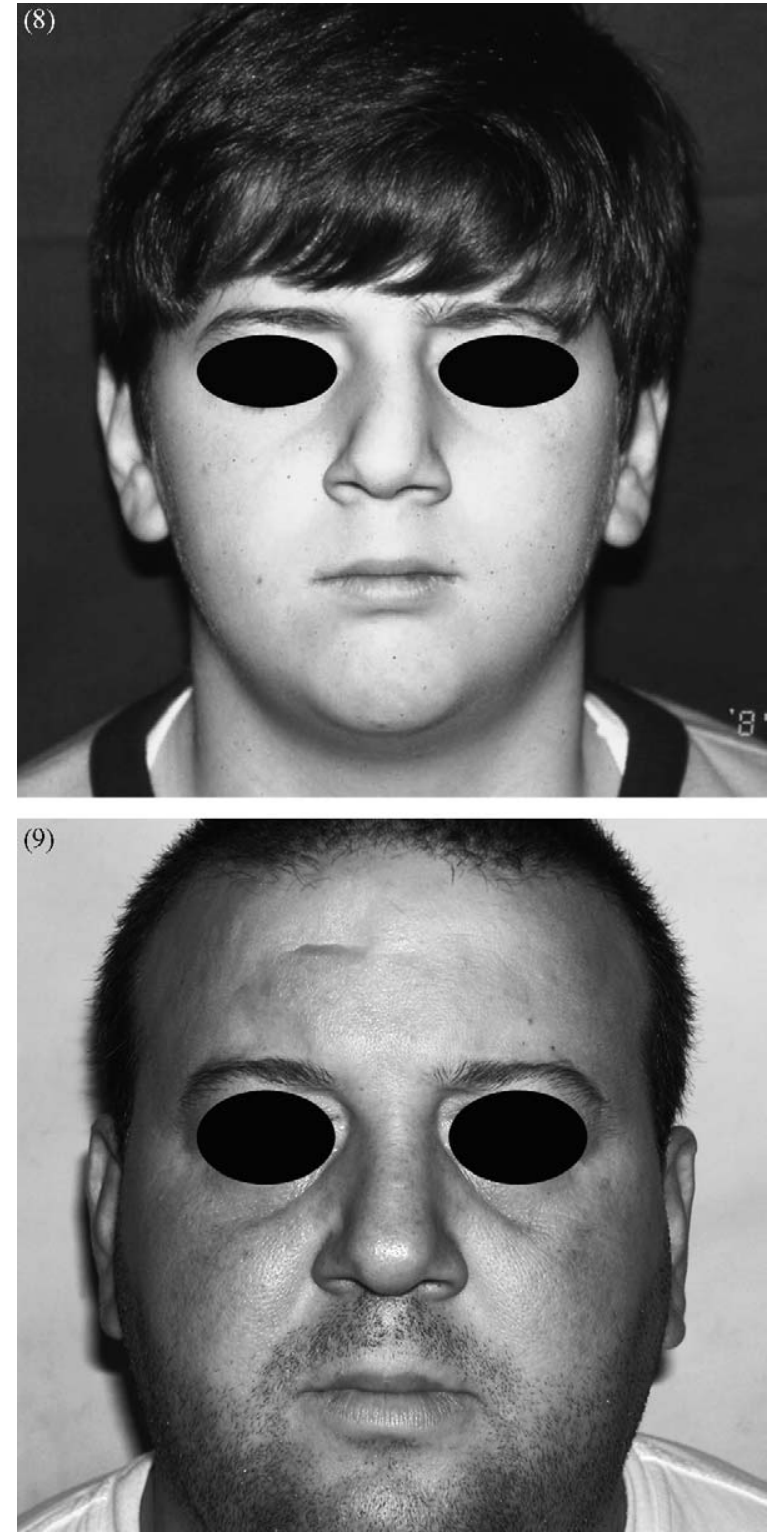

Figs. 8 and 9. Group II: 20 years follow-up; no deformity of nasal pyramid is present.

stage, it will lead to consolidation of the defect, thereby affecting the aesthetics and function of the facial skeleton. Because of all these reasons, if on the one hand surgical management seems indicated in cases of difficult nasal breathing, on the other hand there are still controversies about the timing of management, the surgical technique and the extent of surgical approach. It is our opinion that timing of the intervention should not be related to age but to the grade of nasal obstruction. There are different opinions regarding surgical approach and surgical technique to be used in these patients, they are: early correction of septal deviation and scheduling the rhinoplasty after the development is complete; or performing septorhinoplasty at a single stage. In our 
opinion treatment of nasal septum and pyramid deformity have to be done at the same time. Just like how a fractured nasal bone has to be treated promptly, a fractured nasal bone consolidated in abnormal position should also be replaced in the correct position after reopening the old fracture lines. If we follow this protocol, long-term results on completion of nasal development should be the same as with prompt treatment of fractured nasal bones. Cottle's approach (maxilla-premaxilla) is the best option, in our experience. This is because, it allows us to perform targeted dissection of deviated nasal septum and, if necessary, a complete exposure of the entire septum. Jugo reported that the conservative Cottle's technique caused a high incidence of recurrent deviation due to limited surgical field and incomplete linkage between quadrangular and alar cartilages [10]. Such observations imply poor adherence of quadrangular cartilage to the surrounding structures and, during the cicatrisation process, may favour recurrence of the deviation. As a solution to such problems, he proposed, a total reconstruction of nasal septum by an external approach defined as "decortication", adopted first time by Hage [11]. Such techniques demand long surgical time and extensive dissection. Therefore, it should be reserved only for those rare cases having severe deformity of nasal septum [10]. Another technique reported in literature, used by Halstead in 1910 for approaching pituitary gland, is done through a sublabial incision [12]. Healy proposed an open septoplasty by sub-labial approach to manage nasal bone fractures, preserving as much cartilaginous part of the septum as possible [13]. Cases reported in their study showed good reduction of fracture without any disturbance in growth, during follow-up. In a study based on anthropometric measurements of 28 patients affected by severe anterior septal deviation and managed by external septoplasty (removal, remodelling and repositioning of quadrangular cartilage), Bejar reported that such technique had no effect on naso-facial growth, but may disturb the length and development of the nasal dorsum [14]. In our experience [15] reconstructive septal surgery does not cause significant growth retardation in children if the mucoperichondrium is preserved. El-Hakim et al. reported the same opinion using an open approach [16].

Yilmaz was of the opinion that external technique for septoplasty offers no additional advantage as against the hemitransfixion-transfixion incision, but also is more traumatic for the nasal growth [17]. Therefore the less traumatic hemitransfixion-transfixion incision should be preferred in every condition of nasal septum, except in cases of severe septal deviations coexistent with nasal tip deformity. We advocate the hemitransfixion incision approach maintaining the mucoperichondrium integrity as described before.

The objective outcome evaluation by rhinomanometry and acoustic rhinometry has not yet proven to be diagnostically useful, despite fervour of some centers
[18]. For this reason we believe, in accordance with other authors $[18,19]$, that patients subjective feelings is the main outcome measurement of surgery success.

\section{Conclusion}

Obstructing deviation of nasal septum in childhood is an absolute indication for surgical correction. Our series results demonstrated that the best results were obtained when we correct all evident alterations of nasal septum and pyramid at a single stage, irrespective of age. Unsuccessful results seen in our second group suggest that immediate correction of septum alone with delayed management of nasal pyramid deformity leads to a poorer outcome. In such cases the septum, even when adequately corrected, continues to lie between deviated structures and during growth follows a deviated course. Moreover, during the rapid developmental phase (pubertal period) the growth itself can cause additional alteration of already deviated structures. The patients subjective feelings is the main outcome measurement of surgery success.

\section{References}

[1] Van Loosen J, Baatenburg de Jong RJ, Van Zanten GA, Engel T, Lanjewar DN, Van Velzen D. A cephalometric analysis of nasal septal growth. Clin Otolaryngol 1997;22:453-8.

[2] Cottle MH, Loring RM, Fischer GC, Gaynan IE. The maxilla-premaxilla approach to extensive nasal septum surgery. Arch Otolaryngol 1958;68:301-13.

[3] Cottle MH. Nasal surgery in children. Eye Ear Nose Throat 1951;30:32-8.

[4] Huizing EH. Septum surgery in children; indications, surgical techniques, long term results. Rhinology 1979;18:91-100.

[5] Pirsig W. Septal plasty in children: influence on nasal growth. Rhinology 1977;15:193-204.

[6] Gray LP. The development and significance of septal and dental deformity from birth to eight years. Int J Pediatr Otorhinolaringol 1983;6:265-77.

[7] Korantzis A, Cardamakis E, Cheildonis E, Papamihalis T. Nasal septum deformity in the newborn infant during labour. Eur J Obstet Gynecol Reproduct Biol 1992;44:41-6.

[8] Linder-Aronson S. Effect of adenoids on airflow, facial skeleton and dentition. Acta Otolaryngol 1970;265(suppl):1-130.

[9] Deshayes MJ. Crescita cranio-facciale e ortodonzia. Italia: Masson; 1987.

[10] Jugo SB. Total septal reconstruction through decortication (external) approach in children. Arch Otolaryngol 1987;113:173-8.

[11] Hage J. Surgical approach to the external and internal nose: with a supplementary reportlon two cases of nasal glioma. Br J Plast Surg 1960;12:327-39.

[12] Halstead AE. Remarks on the operative treatment of tumors of the hypophysis: report of two cases operated on by an oto-nasal method. Surg Gynecol Obstet 1910;10:494-8.

[13] Healy G. An approach to the nasal septum in children. Laryngoscope 1986;96:1239-42.

[14] Bejar I, Farkas LG, Messner AH, Crysdale WS. Nasal growth after external septoplasty in children. Arch Otolaryngol 1996;122:81621 . 
[15] Dispenza C, Saraniti C, Dispenza F, Caramanna C, Salzano FA. Management of nasal septal abscess in childhood: our experience. Int J Pediatr Otorhinolaryngol 2004;68:1417-21.

[16] El-Hakim H, Crysdale WS, Abdollel M, Farkas LG. A study of anthropometric measures before and after external septoplasty in children: a preliminary study. Arch Otolaryngol Head Neck Surg 2001;127:1362-6.
[17] Yilmaz T. Septoplasty in children. Arch Otolaryngol 1997;123.

[18] Dinis PB, Haider H. Septoplasty: long-term evaluation of results. Am J Otolaryngol 2002;23:85-90.

[19] Stewart MG, Smith TL, Weaver EM, Witsell DL, Yueh B, Hannley MT, et al. Outcomes after nasal septoplasty: results from the nasal obstructing septoplasty effectiveness (NOSE study). Otolaryngol Head Neck Surg 2004;130:283-90. 